\title{
Inactivation of CK1a in multiple myeloma empowers drug cytotoxicity by affecting AKT and $\beta$-catenin survival signaling pathways
}

\author{
Sabrina Manni ${ }^{1,2}$, Marilena Carrino ${ }^{1,2}$, Martina Manzoni ${ }^{3,4}$, Ketty Gianesin ${ }^{1,2}$, Sara \\ Canovas Nunes ${ }^{1,2}$, Matteo Costacurta ${ }^{1,2}$, Laura Quotti Tubi ${ }^{1,2}$, Paolo Macaccaro ${ }^{1,2}$, Elisa \\ Taiana $^{3,4}$, Anna Cabrelle ${ }^{2}$, Gregorio Barilà ${ }^{1,2}$, Annalisa Martines ${ }^{5}$, Renato Zambello ${ }^{1,2}$, \\ Laura Bonaldi ${ }^{5}$, Livio Trentin ${ }^{1,2}$, Antonino Neri ${ }^{3,4}$, Gianpietro Semenzato ${ }^{1,2}$, Francesco \\ Piazza ${ }^{1,2}$ \\ ${ }^{1}$ Department of Medicine, Hematology and Clinical Immunology Section, University of Padova, Padova, Italy \\ ${ }^{2}$ Venetian Institute of Molecular Medicine, Padova, Italy \\ ${ }^{3}$ Department of Oncology and Hemato-Oncology, University of Milano, Milano, Italy \\ ${ }^{4}$ Hematology Unit, Fondazione IRCCS Ca' Granda, Ospedale Maggiore Policlinico, Milano, Italy \\ ${ }^{5}$ Immunology and Molecular Oncology Unit, Veneto Institute of Oncology, IOV-IRCCS- Padova, Italy \\ Correspondence to: Sabrina Manni, email: sabrina.manni@unipd.it \\ Francesco Piazza, email: francesco.piazza@unipd.it
}

Keywords: CK1a, multiple myeloma, lenalidomide

Received: September 07, $2016 \quad$ Accepted: January 07, $2017 \quad$ Published: January 14, 2017

\section{ABSTRACT}

Recent evidence indicates that protein kinase CK1a may support the growth of multiple myeloma (MM) plasma cells. Here, by analyzing a large cohort of MM cases, we found that high CK1a mRNA levels are virtually associated with all MM patients. Moreover, we provided functional evidence that CK1a activity is essential for malignant plasma cell survival even in the protective niche generated by co-cultures with bone marrow stromal cells. We demonstrated that CK1a inactivation, while toxic for myeloma cells, is dispensable for the survival of healthy B lymphocytes and stromal cells. Disruption of CK1a function in myeloma cells resulted in decreased Mdm2, increased p53 and p21 and reduced expression of $\beta$-catenin and AKT. These effects were mediated partially by p53 and caspase activity. Finally, we discovered that CK1a inactivation enhanced the cytotoxic effect of both bortezomib and lenalidomide. Overall, our study supports a role for CK1a as a potential therapeutic target in MM in combination with proteasome inhibitors and/or immunomodulatory drugs.

\section{INTRODUCTION}

Multiple myeloma (MM), the second most frequent hematologic neoplasia accounting for about $10-15 \%$ of all blood tumors [1], is characterized by the progressive growth of malignant clonal plasma cells (PCs) in the bone marrow (BM) where they find a favourable microenvironmental niche. Often myeloma cells develop resistance to therapy, likely due to a continuous selection of more biologically aggressive subclones [2].

Among the several signalling pathways regulating MM cell growth, the Wnt/ $\beta$-catenin and the PI3K/ AKT cascades are of particular importance for MM expansion. PCs from MM patients and human MM cell lines (HMCLs) express Frizzled receptors and LRP5/6 co-receptors, as well as high levels of phosphorylated AKT on Ser473, which depends on mTOR activity [3]. Both $\beta$-catenin and AKT act as oncogenes and display an increased activity in a wide variety of malignant tumors, including MM [4, 5]. Moreover, BM stromal cells (BMSC) release Wnt or other growth factors which can potentially contribute to MM cell drug resistance $[4,6]$, triggering $\beta$-catenin and the PI3K/AKT signalling [7].

Protein kinase $\mathrm{CK} 1$ is a highly conserved family of monomeric serine/threonine kinases composed by seven members $(\alpha, \beta, \gamma 1, \gamma 2, \gamma 3, \delta, \varepsilon)$ which display the highest homology in their kinase domain (50-90\% identical) with overlapping substrate specificity. CK1 
members regulate membrane biology, molecule transport, signal transduction, transcription, translation and DNAdamage response [8-10]. CK1 $\alpha$, which is encoded by the CSNK1A1 gene, mapping on chromosome 5 at $5 \mathrm{q} 32$, regulates the $\mathrm{Wnt} / \beta$-catenin signalling pathway. CK1 $\alpha$ phosphorylates $\beta$-catenin at Ser45, priming it for the subsequent protein kinase GSK3-dependent phosphorylation at Ser33/37/Thr41, which tags the protein for proteasome-mediated degradation [11]. However, CK1 $\alpha$ may also phosphorylate LRP6, triggering Wntmediated intracellular signalling [12].

$\mathrm{CK} 1 \alpha$ is also a regulator of the AKT pathway. It has been reported that in human embryonic kidney cells CK $1 \alpha$ phosphorylates DEPTOR (an mTOR inhibitor), which is then targeted to the proteasome, thus activating mTORmediated survival pathways $[13,14]$. Since mTOR in turn regulates AKT activation [15], CK1 $\alpha$ could indirectly modulate AKT function.

$\mathrm{CK} 1 \alpha$ also phosphorylates the tumor suppressor p53 [16] and stimulates the binding of murine double minute chromosome 2 (Mdm2) to p53, therefore inhibiting p53 function $[17,18]$. In mouse models, CK1 $\alpha$ loss of function in intestinal epithelial cells caused a strong activation of the Wnt pathway, however it did not lead to tumor formation as long as p53 function remained intact $[19,20]$. On the opposite, in a murine acute leukemia (AML) model, CK1 $\alpha$ loss of function resulted in a dramatic disadvantage for the leukemic clone growth, provided the presence of an intact p53 function [21]. Furthermore, the role of $\mathrm{CK} 1 \alpha$ in mediating tumor cell survival is supported by the finding that treatment with the immunomodulatory drug (iMID) lenalidomide (Lena) induced the E3 ubiquitin ligase CUL4-RBX1-DDB1CRBN (CRL4 ${ }^{\mathrm{CRBN}}$ )-mediated ubiquitination of CK1 $\alpha$ in $\operatorname{del}(5 q)$ myelodysplastic syndromes (MDS), in which one CSNK1A1 allele is lost, with degradation of the residual $\mathrm{CK} 1 \alpha$ protein [22].

To inhibit CK1 $\alpha$ activity, specific small ATPcompetitive molecules have been developed. D4476 (4-[4-(2,3-Dihydro-1,4-benzodioxin-6-yl)-5-(2-pyridinyl)1H-imidazol-2-yl]benzamide) is a cell-permeant inhibitor specific for CK1. It has been demonstrated that D4476 does not inhibit other important kinases (like ERK2, JNK, MSK1, PDK1 and PKA) and it is the best CK1 inhibitor commercially available [23].

More recently, it has been demonstrated that CK $1 \alpha$ also sustains MM cell survival [24]. Here, we investigated CSNK1A1 mRNA expression in a large microarray dataset of MM cases and analyzed CK1 $\alpha$ role in MM cell growth, also in BM microenvironment models. We found that CK1 $\alpha$ inhibition/silencing causes cell cycle arrest and apoptosis of MM cells in a p53-Mdm2 dependent manner, overcoming BMSC-dependent protection. Mechanistically, CK $1 \alpha$ inhibition caused downregulation of the $\beta$-catenin and AKT survival pathways and empowered the cytotoxic and cytostatic effect of bortezomib (BZ) and Lena.

\section{RESULTS}

\section{CK1 $1 \alpha$ expression and cellular localization is different between MM cells and normal cells}

In most available gene expression profiling (GEP) datasets we found that CSNK1A1 mRNA is significantly overexpressed throughout the progression from normal to highly malignant PCs (Oncomine ${ }^{\mathrm{TM}}$ ) [25-27]. Also, CSNK1A1 mRNA was found overexpressed in XBP1sexpressing transformed PCs from transgenic mice [28]. To further validate these data, we investigated GEP data of BM plasma cells obtained from 4 healthy controls, 129 MM, 36 plasma cell leukemia (PCL) patients, and $18 \mathrm{MM}$ cell lines. More than $90 \%$ of malignant plasma cells cases overexpressed CSNK1A1 mRNA compared to controls (Figure 1A). We next performed a correlation between CSNK1A1 mRNA expression and the different molecular groups included in the TC classification: TC1, characterized by the $\mathrm{t}(11 ; 14)$ or $\mathrm{t}(6 ; 14)$ with high expression of $C C N D 1$ or $C C N D 3$; $\mathrm{TC} 2$, characterized by absence of IGH translocation, low levels of CCND1 and hyperdiploid status; TC3, characterized by absence of IGH translocation and CCND2 expression; TC4, showing high level of $C C N D 2$ and the presence of $\mathrm{t}(4 ; 14)$; TC5, expressing the highest level of CCND2 in association with MAF translocations [29, 30]. CSNK1A1 mRNA was significantly higher in TC2 samples compared to the other TC groups (Figure 1B). We have also evaluated the absolute transcript levels of CSNK1A1 in 17 symptomatic MM and 2 primary PCL patients, included in GSE66293 proprietary dataset [31], investigated at diagnosis and first relapse. No significant difference in CSNK1A1 mRNA expression was observed between these two conditions (Figure 1C). To further corroborate the mRNA data, we next performed a survey of $\mathrm{CK} 1 \alpha$ protein expression in purified CD138 malignant PCs from MM patients and HMCLs showing high CK $1 \alpha$ protein levels expression in all the samples analyzed (Figure 1D; Table 1A summarizes the clinical features of the MM patients investigated in this set of experiments). Densitometric analysis of $\mathrm{CK} 1 \alpha$ protein expression confirmed that there is no difference between newly diagnosed and relapsed patients (Figure 1E).

Previous studies reported that CK $1 \alpha$ is detected in all cellular compartments and that its subcellular distribution is cell-cycle dependent [32]. We found that $\mathrm{CK} 1 \alpha$ localized mainly in the cytoplasm of healthy B lymphocytes, while it was present both in the cytoplasm and in the nucleus of malignant PCs from MM and PCL patients and in all the HMCLs tested (Supplementary Figure 1). This different localization of CK $1 \alpha$ was present also in a MM cell line, called SaMMi, which was generated in our laboratory from a primary tumor (see Table 2 for details). 


\section{CK1 $1 \alpha$ inhibition causes MM cell apoptosis even in the presence of BMSCs}

To confirm that high levels of CK1 $\alpha$ kinase in MM are functionally relevant, we treated MM cells with the CK1 inhibitor D4476 at different concentrations for as long as $48 \mathrm{~h}$. Annexin V/PI staining and FACS analysis showed that MM cells exposed to D4476 underwent a remarkable amount of apoptosis starting from the concentration of $10 \mu \mathrm{M}$ for INA-6 (the most sensitive MM cell line) reaching $40 \mu \mathrm{M}$ for H929 and U-266 (the least sensitive). SaMMi cells were also very responsive to D4476-induced apoptosis at a concentration as low as $5 \mu \mathrm{M}$. D4476 induced MM cell apoptosis both in IL-6/stroma dependent (INA-6, SaMMi, U-266) and independent (H929) HMCLs. Treatment with the vehicle alone (DMSO) did not cause a significant amount of apoptosis compared to untreated cells (Figure 2A). To test
A
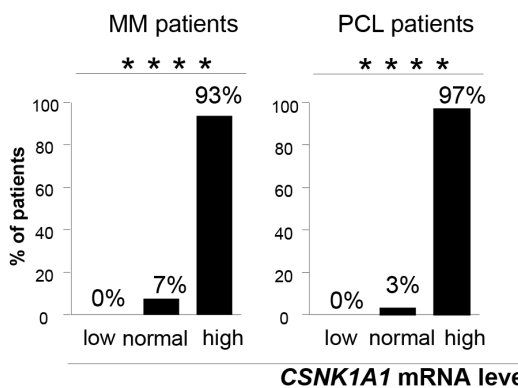

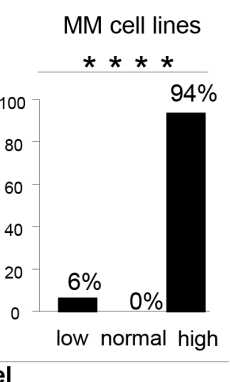

B



C

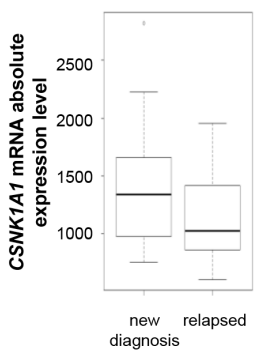

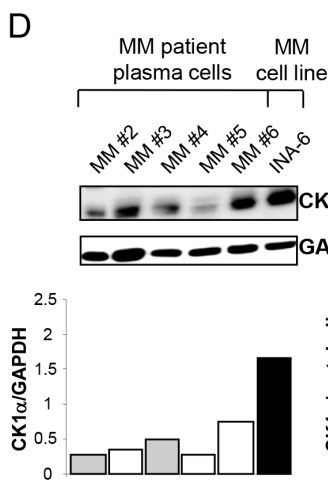

MM patient
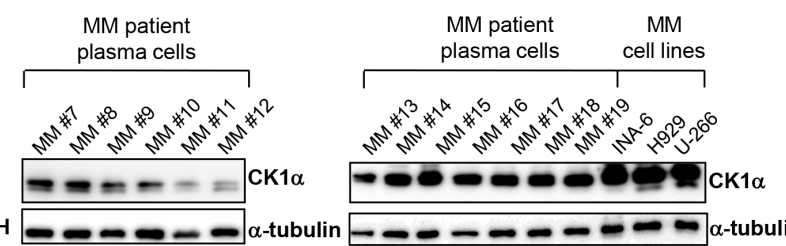
MM
cell line

MM patient plasma cells cell line
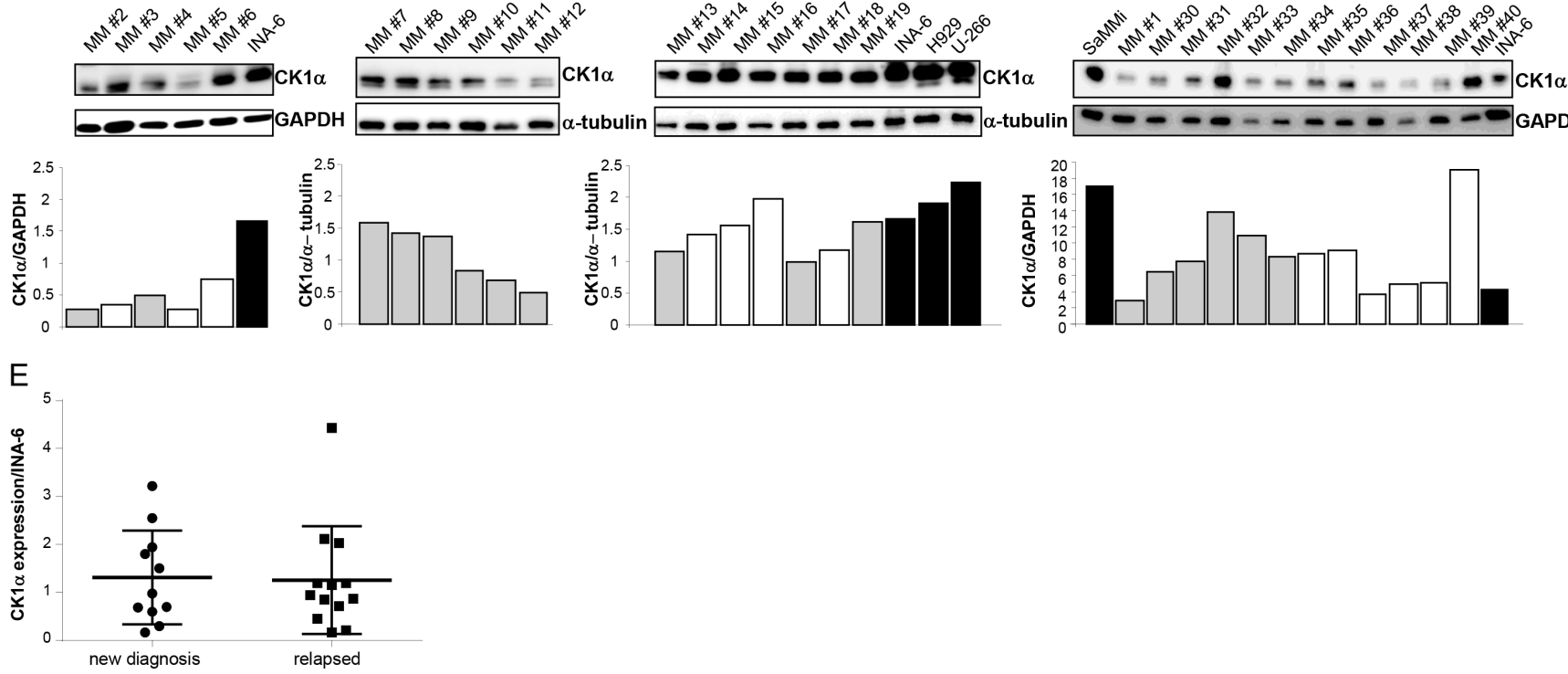

Figure 1: CK1 $\alpha$ mRNA and protein expression in MM patients and cell lines. (A) CSNK1A1 mRNA expression analysis on 129 MM patients (pts) PCs (left panel), 36 PCL patients PCs (middle panel), 18 MM cell lines (right panel), compared to CSNK1A1 mRNA expression level of 4 healthy controls PCs. All primary malignant PCs were purified from diagnostic BM aspirates. Samples were stratified according to CSNK1A1 mRNA expression as follow: normal (value = mean of controls \pm 2 SD), low (value $<$ mean of controls 2SD) and high (value > mean of controls + 2SD). The HMCLs used were UTMC2, KMS12BM, LP1, INA-6, CMA-03, DELTA 47, H929, KMS11, OPM2, RPMI-8226, KMS34, MM.1.144, KMS20, KMS26, KMS18, U266, CMA-0306, MM1S, listed according to CSNK1A1 expression, having UTMC2 the lowest and MM1S the highest expression. Among those, UTMC2 was the only one that had CSNK1A1 mRNA expression level lower than controls. $* * * *=p<0.0001$ according to the Chi square test for trend. (B) Box plot of CSNK1A1 absolute expression level as detected by GEP in 4 healthy donors (N) and different MM TC groups: TC1 (34 pts), TC2 (30 pts), TC3 (40 pts), TC4 (19 pts); TC5 (6 pts). $p=1.454 \times 10^{-6}$ was calculated by Kruskal-Wallis test. (C) Box plot of CSNK1A1 absolute expression level as detected by GEP in 17 symptomatic MM and 2 primary PCL patients, included in GSE66293 proprietary dataset [31] investigated at diagnosis and first relapse. Patients were treated with BZ- based therapeutic regimens. No significant difference was observed between at diagnosis and relapsed samples $(p=0.212)$ using Wilcoxon signed-rank test. (D) WB analysis (upper panel) and the corresponding densitometry values of CK $1 \alpha$ expression in $30 \mathrm{MM}$ patient derived CD138 PCs and in HMCLs INA-6, U-266, H929 and SaMMi. Grey bars represent newly diagnosed patients, white bars represent relapsed patients and black bars are cell lines. GAPDH or $\alpha$-tubulin was used as a loading control. (E) Densitometric analysis of CK1 $\alpha$ protein expression of MM patients described in D, grouped in new diagnosis and relapsed MM patients. Values are normalized over CK1 $\alpha$ expression of INA-6 cell line. 
the effects of D4476 in control cells, we treated PBMCs from healthy donors with D4476 at different doses for $48 \mathrm{~h}$ and analyzed apoptosis in the $\mathrm{CD} 19^{+}$fraction by flow cytometry. The CK1 inhibitor did not cause any significant changes in apoptosis of $\mathrm{CD} 19^{+}$healthy B lymphocytes at any concentration used compared to DMSO treated cells, indicating no toxicity for normal B cells (Figure 2B). Also D4476 treated CD138 ${ }^{+}$PCs isolated from seven MM patients underwent, on average, a significant amount of apoptosis compared to untreated cells (Figure 2C). When CK1 inhibition was tested also in a model of protective microenvironment [33] we observed that BMSCs were not able to protect INA-6 or SaMMi MM cells from D4476-induced cell death (Figure 2D-2E). To note, HS-5 stromal cells protected SaMMi from doxorubicin-induced apoptosis (Supplementary Figure 2) showing that also this new cell line is suitable for the BM microenvironment model experiments. CK1 blockade had cytotoxic consequences mainly on malignant PCs, since HS-5 cells were spared by D4476-induced cytotoxicity (data not shown). Most importantly, the apoptotic effect of D4476 was also found in patient-derived PCs co-cultured with HS-5 or patient-derived BMSCs (Figure 2F-2G; see Table 1B for clinical features of patients). To note, even though we observed higher protection by patient-derived BMSCs compared to the HS-5 stromal cell line, D4476 was still able to induce MM cell apoptosis. These results suggest a pro-survival role of CK1 for MM cells also in the BM microenvironment context.

\section{CK1 blockade associates with activation of a p53-dependent apoptotic cascade}

D4476-induced apoptosis was accompanied by increased expression levels of pro-apoptotic proteins (Bax, Bak, cleaved PARP) and decreased expression of the pro-survival molecule Mcll (Supplementary Figure $3 \mathrm{~A}$ ). It was previously shown that $\mathrm{CK} 1 \alpha$ promotes p53 degradation in different cell types $[16,17]$. Indeed, also in INA-6, U-266, and SaMMi MM cells, D4476 caused an increase of $\mathrm{p} 53$ protein levels with a consequent upregulation of its target $\mathrm{p} 21$ and a reduction of $\mathrm{Mdm} 2$ protein (Supplementary Figure 3B). Altogether, these findings support the view that D4476-induced apoptosis could be mediated by the activation of a p53-dependent response.

\section{CK1 $1 \alpha$ silencing causes apoptosis and cell cycle arrest}

To validate the results obtained with the chemical inhibition of $\mathrm{CK} 1 \alpha$, we used RNA interference (RNAi) to knockdown CK1 $\alpha$ protein in INA-6 and H929 cells. As shown in Figure 3, CK1 $\alpha$ knockdown (obtained both with electroporation of double strand (ds) siRNA or through the generation of IPTG inducible CSNK1A1 specific shRNAs- see methods) determined a boost of apoptosis in INA-6 cells grown alone (Figure $3 \mathrm{~A}-3 \mathrm{~B}$ ), or in the presence of protective stromal HS-5 (Figure 3C). To check the effects of $\mathrm{CK} 1 \alpha$ knockdown also in the BM microenvironment context, we pre-treated INA- 6 clones with IPTG for 6 days to induce the silencing of CK $1 \alpha$. Afterwards, control and silenced cells where co-cultured with HS-5 for additional 4 days (in the presence or absence of IPTG). CK $1 \alpha$ knockdown determined an increase of apoptosis also in the context of the microenvironment, as shown by the increase in the amount of Annexin V positive cells, a raise of PARP cleavage and decrease of Mcl1 protein expression level (Figure 3C), therefore overcoming stromal cells protection. The apoptotic effect of CK $1 \alpha$ silencing was observed also in H929 cells (Figure 3D-3E). In all samples, immunoblot analysis confirmed that CK1 $\alpha$ was efficiently knocked down. Of note, IPTG treatment did not change CK $1 \alpha$ expression levels and the apoptotic rate in wt INA-6 or H929 cells compared to untreated cells, confirming the efficacy/specificity of the silencing strategy (Figure 3B-3E). The pro-apoptotic effect of CK $1 \alpha$ knockdown was further confirmed by cell cycle analysis. CK1 $\alpha$ silencing determined an increase in the sub-G1 (apoptotic) phase and a reduction in G0/ G1 phase of the cell cycle (Supplementary Figure 4A), accompanied by a reduction of $\mathrm{Mdm} 2$ and an increase of p21, (Supplementary Figure 4B) confirming the activation of a p53-dependent cell cycle arrest.

\section{Inhibition of CK1 $\alpha$ leads to a caspase-dependent $\beta$-catenin and AKT degradation}

Since $\beta$-catenin and AKT signalling pathways are crucial for MM pathobiology, and given the role of CK $1 \alpha$ in modulating their activity in other cell types, we sought to investigate the role of CK $1 \alpha$ on $\beta$-catenin and AKT transduction cascades in MM. H929, INA-6 and MM patient-derived plasma cells (grown alone or in co-culture with HS-5 or MM BMSCs) were treated with the indicated concentrations of D4476 and WB analysis was carried on. After CK1 inhibition, a reduction of phosphorylated $\beta$-catenin on Ser 45 and on Ser33/37/Thr41 and of phosphorylated AKT on Ser473 was observed in all the tested cells (Figure 4A-4C). However, unexpectedly, a reduction of total $\beta$-catenin and AKT protein levels was also observed, which could account for the lowering of the phosphorylated forms. RNAi of CK1 $\alpha$ in two MM cell lines led to similar effects (Figure 4D-4E). To test if the observed reduction of $\beta$-catenin and $\mathrm{AKT}$ induced by $\mathrm{CK} 1 \alpha$ inactivation was proteasome dependent, we treated H929 and INA-6 cells grown alone or in co-culture with HS-5 with D4476 for $48 \mathrm{~h}$ and with the proteasome inhibitor BZ for $18 \mathrm{~h}$. D4476 prevented BZ-induced accumulation of $\beta$-catenin and AKT, indicating that the observed D4476-induced $\beta$-catenin and AKT decrease was not mediated by the proteasome (Figure 5A). 
Table 1: Clinical and pathological features of MM patients analyzed

\begin{tabular}{|c|c|c|c|c|c|c|c|c|c|}
\hline Sample & Age & Sex & $\begin{array}{l}\text { DS } \\
\text { Stage }\end{array}$ & $\begin{array}{l}\text { ISS } \\
\text { Stage }\end{array}$ & Paraprotein Type & $\%$ PCs & Karyotype & New Diagnoses & $\begin{array}{c}\text { Bone } \\
\text { Disease }\end{array}$ \\
\hline \multicolumn{10}{|l|}{ (A) } \\
\hline MM 1 (SaMMi) & 81 & $\mathrm{~F}$ & IA & III & Micromolecular, $\lambda$ & 20 & $\begin{array}{c}\text { Abnormal karyotype; chr. } 1 \text { rearrangement; } \\
\mathrm{t}(11 ; 14)\end{array}$ & $\mathrm{Y}$ & $\mathrm{N}$ \\
\hline MM 2 & 81 & $\mathrm{~F}$ & IA & III & $\mathrm{IgG} / \mathrm{k}$ & 46 & Normal & $\mathrm{Y}$ & $\mathrm{N}$ \\
\hline MM 3 & 60 & $\mathrm{~F}$ & IIA & II & $\mathrm{IgG} / \mathrm{k}$ & 80 & Normal & $\mathrm{N}$ & $\mathrm{Y}$ \\
\hline MM 4 & 77 & $\mathrm{~F}$ & IIA & I & $\operatorname{IgA} / \mathrm{k}$ & 36.9 & $59 \% \operatorname{del}(17 p)$ & $\mathrm{Y}$ & $\mathrm{Y}$ \\
\hline MM 5 & 74 & M & IA & III & $\mathrm{IgG} / \mathrm{k}$ & 63.8 & $\operatorname{del}(13 q)$ & $\mathrm{N}$ & $\mathrm{N}$ \\
\hline MM 6 & 58 & $\mathrm{M}$ & IIIA & $\mathrm{I}$ & $\mathrm{IgG} / \lambda$ & 20 & Normal & $\mathrm{N}$ & $\mathrm{Y}$ \\
\hline MM 7 & 72 & M & IIA & I & $\mathrm{IgG} / \mathrm{k}$ & 30 & $\operatorname{del}(17 p)$ & Y & $\mathrm{Y}$ \\
\hline MM 8 & 58 & $\mathrm{M}$ & IIIA & III & $\operatorname{IgA} / \mathrm{k}$ & 16 & Monosomy $13(90 \%)$ & $\mathrm{Y}$ & Y \\
\hline MM 9 & 71 & $\mathrm{~F}$ & IIIA & III & $\mathrm{IgG} / \mathrm{k}$ & 19 & Normal & $\mathrm{Y}$ & $\mathrm{Y}$ \\
\hline MM 10 & 76 & $\mathrm{M}$ & IIA & III & $\mathrm{IgG} / \mathrm{k}$ & 45 & IgH rearrangement & $\mathrm{N}$ & $\mathrm{N}$ \\
\hline MM 11 & 74 & M & IIIA & II & $\mathrm{IgG} / \lambda$ & 56 & $\begin{array}{c}\text { Trisomy 1q, 7, 13, 19,22; } \\
\text { tetrasomy } 15, \operatorname{del}(8 \mathrm{p}), \operatorname{del}(8 \mathrm{p}), \mathrm{t}(2 ; 3)\end{array}$ & $\mathrm{Y}$ & $\mathrm{Y}$ \\
\hline MM 12 & 64 & M & IIIB & III & $\operatorname{IgD} / \lambda$ & 80 & $\begin{array}{l}\text { Complex karyotype; } \mathrm{t}(11 ; 14), \mathrm{t}(1 ; 14), \\
\operatorname{del}(13)\end{array}$ & $\mathrm{Y}$ & $\mathrm{Y}$ \\
\hline MM 13 & 71 & $\mathrm{~F}$ & IIA & $\mathrm{I}$ & $\mathrm{IgG} / \lambda$ & 30 & Partial del(1); partial 1q trisomy & $\mathrm{Y}$ & $\mathrm{Y}$ \\
\hline MM 14 & 60 & M & IIIA & I & $\mathrm{IgG} / \mathrm{k}$ & 40.6 & IgH rearrangement, del(13q) & $\mathrm{N}$ & $\mathrm{Y}$ \\
\hline MM 15 & 68 & $\mathrm{~F}$ & IA & $\mathrm{I}$ & $\mathrm{IgG} / \lambda$ & 50 & Normal & $\mathrm{N}$ & $\mathrm{N}$ \\
\hline MM 16 & 60 & $\mathrm{~F}$ & IA & I & $\operatorname{IgA} / \lambda$ & 51.7 & $\begin{array}{l}\text { Complex karyotype; del }(1 \mathrm{p}) ; \\
\text { presence of hyperdiploid clones }\end{array}$ & $\mathrm{N}$ & $\mathrm{Y}$ \\
\hline MM 17 & 67 & $\mathrm{~F}$ & IIIA & III & Non secretory & 100 & Monosomy $13(76 \%)$ & $\mathrm{Y}$ & $\mathrm{Y}$ \\
\hline MM 18 & 68 & $\mathrm{~F}$ & IIIA & III & Micromolecular, $\mathrm{k}$ & 80 & Normal & $\mathrm{N}$ & $\mathrm{Y}$ \\
\hline MM 19 & 69 & M & IIIA & II & Micromolecular, $\mathrm{k}$ & 60 & del(13q), MAF+, IgH-/+ & $\mathrm{Y}$ & $\mathrm{Y}$ \\
\hline MM 20 & 71 & M & IIIA & III & $\mathrm{IgG} / \lambda$ & 90.1 & $\operatorname{del}(\mathrm{Y}), \operatorname{del}(13 \mathrm{q})$ & $\mathrm{N}$ & Y \\
\hline MM 21 & 81 & M & IIIA & II & Micromolecular, $\lambda$ & 35 & NA & $\mathrm{Y}$ & $\mathrm{Y}$ \\
\hline MM 22 & 76 & $\mathrm{~F}$ & IIIA & I & $\mathrm{IgG} / \mathrm{k}$ & 95 & Trisomy $5,6,9,11,15,21$ & $\mathrm{Y}$ & $\mathrm{Y}$ \\
\hline MM 29 & 44 & M & IIIB & III & $\operatorname{IgA} / \lambda$ & 24 & $\begin{array}{l}\text { Complex karyotype; Monosomy 13, 14, } \\
90 \% \operatorname{del}(17 \mathrm{p}) ; \text { Chr. } 1 \text { rearrangements, gain } \\
\text { of 1q }\end{array}$ & $\mathrm{N}$ & $\mathrm{Y}$ \\
\hline MM30 & 76 & M & IA & NA & $\mathrm{IgG} / \mathrm{k}$ & 60 & Normal karyotype, IgH rearr., trisomy 17 & $\mathrm{Y}$ & $\mathrm{N}$ \\
\hline MM31 & 72 & $\mathrm{~F}$ & IIIA & III & $\mathrm{IgG} / \lambda$ & 100 & Complex karyotype, hyperploid; del(13q) & $\mathrm{Y}$ & $\mathrm{N}$ \\
\hline MM32 & 67 & $\mathrm{M}$ & IIIA & II & $\operatorname{IgG} / \lambda$ & 100 & NA & $\mathrm{Y}$ & $\mathrm{Y}$ \\
\hline MM33 & 75 & M & IIIB & III & $\mathrm{IgG} / \lambda$ & $40-100$ & Hypodiploid, $\mathrm{t}(14 ; 16)$, del(13q), gain of $1 \mathrm{q}$ & $\mathrm{Y}$ & $\mathrm{N}$ \\
\hline MM34 & 74 & $\mathrm{M}$ & IIIB & III & Micromolecular, $\lambda$ & 100 & IgH-; del(17p), gain of 1q & $\mathrm{Y}$ & $\mathrm{Y}$ \\
\hline MM35 & 56 & M & IIIA & NA & $\mathrm{IgG} / \lambda$ & 100 & NA & $\mathrm{N}$ & $\mathrm{Y}$ \\
\hline MM36 & 42 & F & IIIA & III & $\operatorname{IgA} / \mathrm{k}$ & 90 & Normal & $\mathrm{N}$ & $\mathrm{Y}$ \\
\hline MM37 & 56 & M & IIIA & I & $\operatorname{IgA} / 1$ & 100 & $\begin{array}{c}\text { Complex karyotype }(+1, \operatorname{del}(1), \operatorname{dic}(1 ; 5), \\
-13,-16,+17 . \text { FISH: del }(1 \mathrm{q}), \operatorname{del}(13 \mathrm{q}), \text { del } \\
\text { FGFR }\end{array}$ & $\mathrm{N}$ & $\mathrm{Y}$ \\
\hline MM38 & 70 & $\mathrm{M}$ & IIA & II & $\mathrm{IgG} / \lambda$ & 20 & NA & $\mathrm{N}$ & $\mathrm{Y}$ \\
\hline MM39 & 74 & M & IIA & II & $\mathrm{IgG} / \mathrm{k}$ & 100 & $46 X Y ; t(11 ; 14) ;$ gain of $1 \mathrm{q}$ & $\mathrm{N}$ & $\mathrm{Y}$ \\
\hline MM40 & 75 & $\mathrm{~F}$ & IIIA & II & $\mathrm{IgG} / \mathrm{k}$ & 100 & $\begin{array}{l}\text { Complex karyotype; del(6p), del(17p), } \\
\text { monosomy } 10,12,13,15,16,17\end{array}$ & $\mathrm{~N}$ & $\mathrm{Y}$ \\
\hline \multicolumn{10}{|l|}{ (B) } \\
\hline MM 8 & 58 & M & IIIA & III & $\operatorname{IgA} / \mathrm{k}$ & 16 & Monosomy 13 (90\%) & $\mathrm{Y}$ & Y \\
\hline MM 14 & 60 & M & IIIA & I & $\mathrm{IgG} / \mathrm{k}$ & 40.6 & $\mathrm{IgH}$ rearrangement, $\mathrm{del}(13 \mathrm{q})$ & $\mathrm{N}$ & $\mathrm{Y}$ \\
\hline MM 23 & 59 & M & IIIA & I & $\mathrm{IgG} / \mathrm{k}$ & 44 & Trisomy $1,5,9,18,19,21$ & $\mathrm{Y}$ & $\mathrm{Y}$ \\
\hline MM 24 & 45 & $\mathrm{~F}$ & IIIA & III & $\mathrm{IgG} / \mathrm{k}$ & 86 & 90\% MAF-/+, Monosomy 13 & $\mathrm{~N}$ & $\mathrm{Y}$ \\
\hline MM 25 & 54 & $\mathrm{~F}$ & IIA & I & $\mathrm{IgG} / \mathrm{k}$ & 22 & $\mathrm{t}(4 ; 14)$, Monosomy 13 & $\mathrm{~N}$ & $\mathrm{Y}$ \\
\hline MM 26 & 74 & $\mathrm{~F}$ & IA & I & $\mathrm{IgG} / \mathrm{k}$ & 26.4 & $\mathrm{t}(14 ; 16)$ & $\mathrm{N}$ & $\mathrm{Y}$ \\
\hline MM 27 & 76 & $\mathrm{~F}$ & IIA & III & $\mathrm{IgG} / \lambda$ & 22.8 & Normal & $\mathrm{N}$ & $\mathrm{Y}$ \\
\hline MM 28 & 75 & $\mathrm{M}$ & IIB & III & $\mathrm{IgG} / \lambda$ & 14 & $36 \% \operatorname{del}(\mathrm{Y})$, Monosomy 13 & Y & Y \\
\hline
\end{tabular}

MM plasma cells (A) and MM BMSC (B) were isolated from bone marrow of patients listed. Clinical staging was performed according to Durie-Salmon criteria and according to the International Staging System (ISS; albumin levels $\leq$ or $>35 \mathrm{~g} / \mathrm{L}$; $\beta 2$-microglobulin levels $\leq$ or $>3.5 \mathrm{mg} / \mathrm{L}$ ). All features are reported as data at diagnosis. $\mathrm{M}=$ Male, $\mathrm{F}=\mathrm{Female}, \mathrm{DS}=$ DurieSalmon, ISS = International Staging System, PC = Plasma Cell, Y = Yes/Present, N = No/Absent, NA = Not Available. 
Table 2: Immunophenotype and cytogenetic features of SaMMi MM cell line

\begin{tabular}{c|c|c|c|c|c|c|c|c|}
\hline Cell type & CD138 & CD38 & CD117 & CD19 & CD56 & CD45 & Mono $\kappa$ & Mono $\lambda$ \\
\hline SaMMi & + & - & - & - & + & + & - & + \\
\hline MM & + & $+/-$ & $+/-$ & - & + & + & $+/-$ & $+/-$ \\
\hline
\end{tabular}

SaMMi was compared with common MM cell lines (MM). Mono $\kappa$ and Mono $\lambda$ refer to clonal restriction for $\kappa$ and $\lambda$ light chain, respectively. The karyotype of SaMMi is the following:

45,X,-X,idic(1)(p11),der(1)t(1;3)(q25;q21),del(4)(q25),t(4;12)(q26;q13),

$\operatorname{der}(14) \mathrm{t}(11 ; 14)(\mathrm{q} 13 ; \mathrm{q} 32) \mathrm{t}(8 ; 14)(\mathrm{q} 23 ; \mathrm{q} 32), \operatorname{der}(9) \operatorname{del}(9)(\mathrm{p} 21) \mathrm{t}(1 ; 18 ; 9)(\mathrm{q} 12 ; \mathrm{p} 11 ; \mathrm{q} 34)[25]$. ish idic(1)

(p11)(CDKN2C-,CKS1B++),der(1)t(1;3)(CDK2C+,CKS1B+)del(17)(p13.1p13.1)(TP53-,

17p11.1-q11.1+),der(18)t(1;18;9)(CKS1B+)[4].

Another AKT or $\beta$-catenin degradation mechanism could involve caspases and the tumor suppressor p53 [34,35]. Previous studies in other cell types, showed a reduction of $\beta$-catenin upon increasing expression and activity of p53 [35]. Moreover, other works described a caspase-dependent (mainly caspase 3,6 and 8) and apoptosis-induced cleavage of $\beta$-catenin $[36,37]$. Therefore, to test if this mechanism could be responsible of $\beta$-catenin and AKT degradation upon CK1 $\alpha$ inhibition also in MM cells, we treated INA- 6 cells with D4476 and the pan-caspase inhibitor Z-VAD-FMK. The addition of Z-VAD-FMK, prevented the D4476-induced reduction of $\beta$-catenin and AKT. The efficacy of the caspase inhibitor was confirmed by Annexin V/PI staining, Pro-caspase 3 and Mcl1 protein detection by WB (Figure 5B). Next, we checked if other p53-inducing agents could correlate with a reduction in $\beta$-catenin expression in MM. Remarkably, doxorubicin determined an upregulation of the p53 axis (p53 and p21 increase, reduction of Mdm2 protein level) with concomitant decrease in total $\beta$-catenin level in INA-6 and H929 (Figure 5C). Taken together, these results suggest that p53 and caspase-mediated apoptosis could be responsible for the D4476-induced reduction of $\beta$-catenin and AKT in MM cells.

\section{CK1 inhibition boosts bortezomib induced cytotoxicity}

Since CK1 $\alpha$ promotes MM cell survival, we sought to investigate if its inhibition could empower the cytotoxicity exerted by bortezomib. To this aim, we first assessed the extent of apoptosis of MM cells exposed in culture to D4476 and BZ. D4476 caused an increase of BZ-induced apoptosis in the BZ sensitive U-266, H929 and INA-6 MM cells (Supplementary Figure 5A-5C). To evaluate the role of $\mathrm{CK} 1 \alpha$ in $\mathrm{BZ}$ resistance, we also treated RPMI-8226 (a less BZ sensitive cell line) with subtoxic doses of BZ ( $5 \mathrm{nM}$ and $7.5 \mathrm{nM}$ ) in association with D4476. In this cell line, higher doses of BZ $(10 \mathrm{nM})$ are needed to obtained BZ-induced cytotoxicity (Supplementary Figure 5D). CK1 inhibition in association with BZ was able to cause a moderately higher level of apoptosis compared to the single treatments and overcome $\mathrm{BZ}$ resistance in these cells. Furthermore, we have treated the UTMC2 cell line (which is reported to be BZ resistant
[38]), with D4476. CK1 inactivation caused a strong dose dependent cytotoxicity in UTMC2 cells without an additive role with BZ. Moreover D4476 cooperated with $\mathrm{BZ}$ in inducing cell death also in the model of BM microenvironment of INA-6 grown in co-cultures with HS-5 or patient-derived BMSCs (Supplementary Figure 5F-5G). Importantly, CK1 inhibition was able to overcome patient BMSCs-induced resistance to BZ (Supplementary Figure 5G). To determine if the inhibition of CK1 and the proteasome could cause either an additive or a synergic effect in terms of cell growth arrest, we performed MTT assay evaluating cell viability after treating $\mathrm{H} 929$ cells with increasing concentration of BZ and D4476 and with the combination of the two compounds. The results showed that treatment of MM cells with BZ and the CK1 inhibitor was strongly synergic (Supplementary Figure 5H), as judged by the calculated Combination Index (CI) well below 1 (0.560). Moreover, we evaluated CK1 $\alpha$ expression in MM patients with regards to BZ sensitivity, by analyzing CSNK1A1 mRNA expression in the public dataset GSE9782 [39]. Patients included in this study were treated with BZ and the dataset consisted of 169 patients evaluable for response. A slight significant difference was evidenced between 85 responder and 84 not responder MM patients, showing higher expression levels of CSNK1A1 in not responder patients (Supplementary Figure 5I).

\section{CK1 $\alpha$ is degraded by lenalidomide and its inhibition/silencing reinforces lenalidomide cytotoxicity}

To investigate if CK1 $\alpha$ inhibition could modify iMIDs induced cytotoxicity, we first treated H929 MM cells with different concentrations of Lena for 4 and 7 days and we confirmed a pro-apoptotic and an antiproliferative/cytostatic effect of Lena in MM cells (Supplementary Figure 6). We next established that Lena causes a dose- and time-dependent degradation of CK1 $\alpha$ protein in $\mathrm{H} 929$ with a subsequent reduction of its kinase activity (a decrease phosphorylation of its target phosphorylated Ser45 $\beta$-catenin was shown) (Figure 6A). A time-dependent Lena-induced degradation of CK1 $\alpha$ 
was confirmed also in U-266 and INA-6 cell lines at even earlier time points ( $4 \mathrm{~h}$ treatment) (Figure 6B, 6C).

Next, Lena sensitive (H929, SaMMi) and insensitive (INA-6) cells were treated with Lena $10 \mu \mathrm{M}$ for 3 or 7 days. Forty-eight hours before harvesting, D4476 was added to the cell culture. D4476 strikingly cooperated with Lena in inducing MM cell death causing an increase of apoptotic cells compared to single treatments (Figure 7A). Interestingly, $\mathrm{CK} 1 \alpha$ inhibition overcome Lena resistance in INA-6 cells. The therapeutic potential of Lena and D4476 was demonstrated also in models of myeloma BM microenvironment. Indeed, Lena potentiated the cytotoxic effect of D4476, overcoming BM protection also in SaMMi cells grown on HS-5 (Figure 7A, right panel).

To test if the two drugs acts in a synergistic mode, we performed the MTT viability assay calculating the CI. H929 cells were treated with increasing doses of Lena or D4476 and with the combination of the two compounds. The CI was 0.705 suggesting a synergy between the CK1 inhibitor and Lena in reducing cell viability (Figure 7B).

Next we evaluated the effect of D4476 and Lena on cell cycle. D4476 plus Lena caused a decrease in the percentage of cells in G1 and in S/G2M phases and an increase in the frequency of sub-G1 apoptotic cells,
A
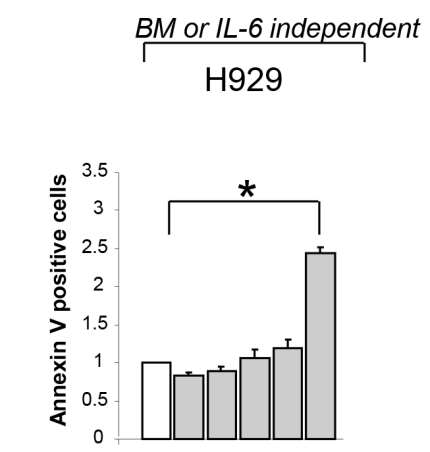

D4476 $(\mu \mathrm{M}):-\quad-5102040$

DMSO: -+++++
B

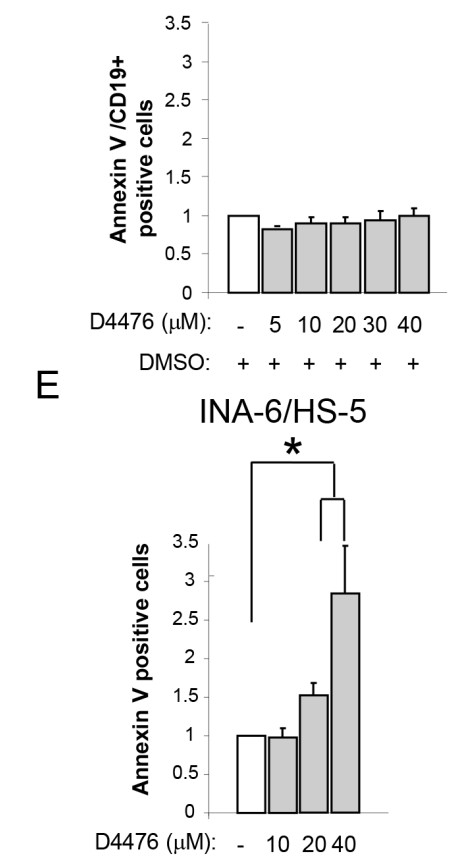

E



Healthy $B$ cells

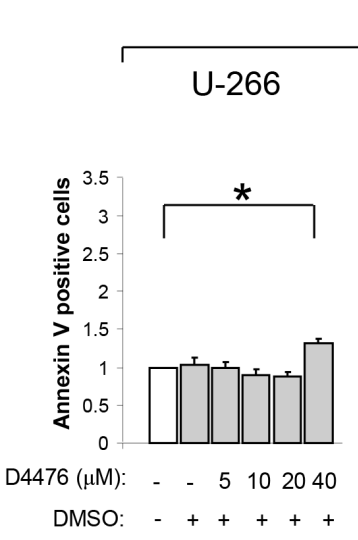

C

MM Patient PC


BM or IL-6 dependent

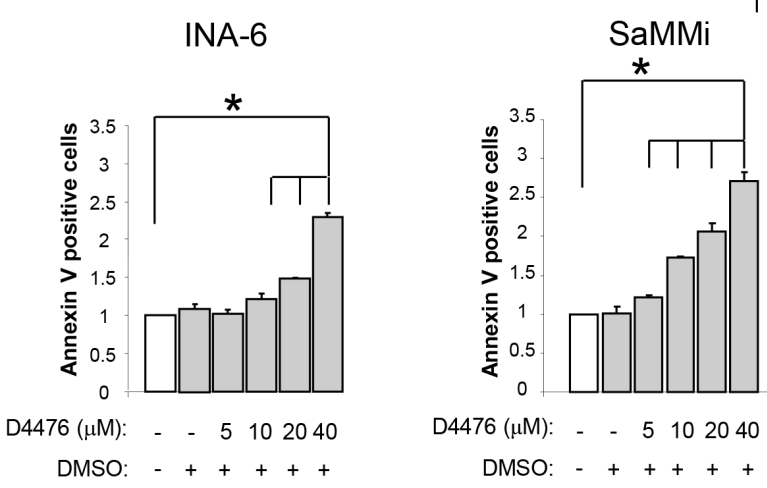

D



G

MM patient $\mathrm{PC} / \mathrm{MM}$ patient BMSC

Figure 2: Effects of CK1 inhibition on MM cell survival. Quantification of apoptosis through Annexin V staining and FACS analysis in various models of MM cells treated with different concentrations of D4476 (ranging from 5 to $40 \mu \mathrm{M})$ for $48 \mathrm{~h}$ : (A) MM cell lines H929, U-266, INA-6, SaMMi; (B) average of 6 purified healthy B cells; (C) 7 independent CD138 MM patient PCs (MM\#11, MM\#16, MM\#8, MM\#20, MM\#21, MM\#22, MM\#29); (D) SaMMi cultured on HS-5 stromal cells (SaMMi/HS-5); (E) INA-6 cultured on HS-5 stromal cells (INA-6/HS-5) and on patient derived BMSCs (INA-6/MM patient BMSC); (F-G) patient derived CD138 ${ }^{+}$plasma cells cultured on HS-5 (MM patient PC/HS-5) or on MM patient derived BMSCs (MM patient PC/MM patient BMSC). Data represent the mean \pm SEM of 3-6 (A), six (B), seven (C), six (D) four-six (E), two (F) seven (G) independent experiments and are presented as arbitrary values over untreated cells. * indicates $p<0.05$. DMSO 0.04\% was also tested to exclude D4476 vehicle induced toxicity. 
compared to the single treatments (Figure 7C). Also Ki-67 staining showed a significant reduction of active proliferating cells in the combined treatment (Figure 7C). Moreover, a raise of $\mathrm{p} 21$ and a decline of $\mathrm{Mdm} 2$ protein levels were stronger in the combination treatment compared to the single treatments (Figure 7D).

Next, we treated CK1 $\alpha$-silenced (with siRNA against CSNK1A1) and control H929 cells with Lena $10 \mu \mathrm{M}$ for 3 days. The combination of Lena and CK $1 \alpha$ silencing determined a stronger reduction of active proliferating cells as judged by a marked decline in the percentage of Ki-67 positive cells as compared to single treatments. An increase in apoptosis and the derangement in the cell cycle were also confirmed by a reduction in the uncleaved PARP, Mdm2 protein and a subsequent increase in $\mathrm{p} 21$. CK1 $\alpha$ silencing empowered Lena induced CK $1 \alpha$ protein degradation with subsequent further reduction in its activity on Ser45 $\beta$-catenin. Moreover, the combination of CK $1 \alpha$ silencing and Lena also effectively decrease AKT phosphorylation and protein level (Figure 8).

\section{DISCUSSION}

In the present study we investigated the expression of $\mathrm{CK} 1 \alpha$ in $\mathrm{MM}$ and provided evidence of its role in sustaining MM cell survival and proliferation. We also demonstrated that $\mathrm{CK} 1 \alpha$ controls the levels of $\beta$-catenin and AKT, likely preventing their p53/caspase-mediated
A

INA-6
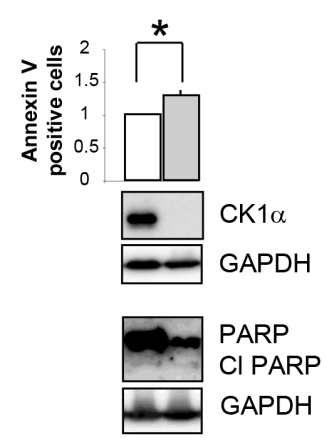

PARP

CI PARP

GAPDH

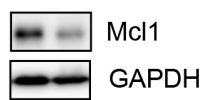

SiRNA CK1 $\alpha$ : - +

siGLO scr : + +

D

H929



B

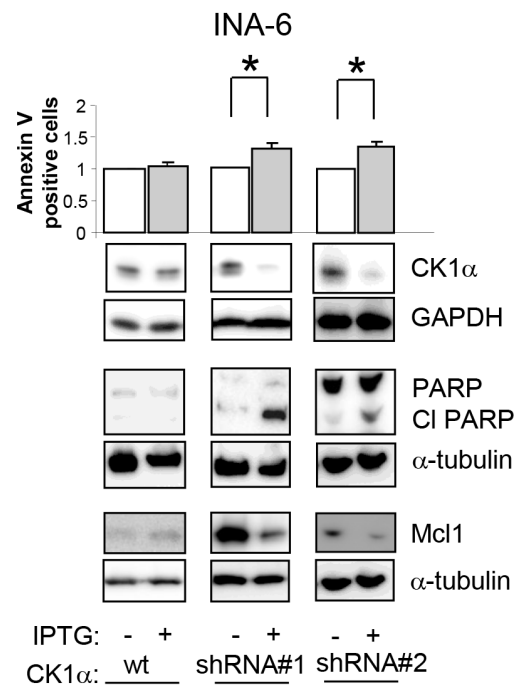

E

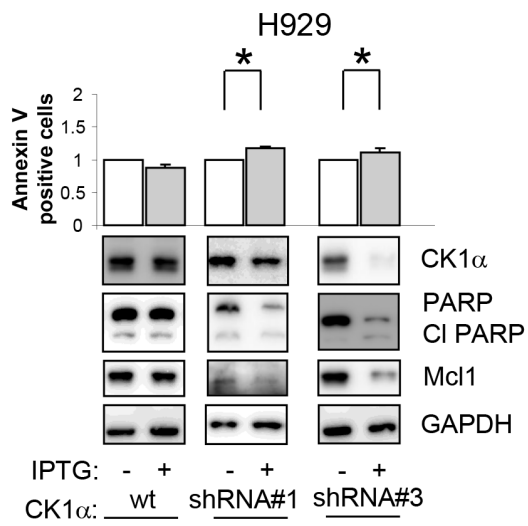

C

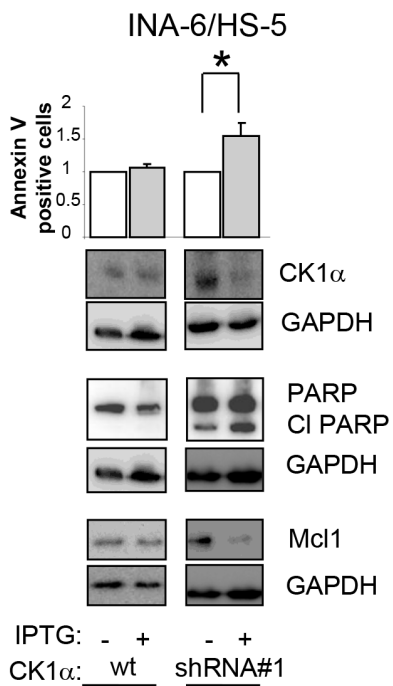

Figure 3: Effects of CK1 inhibition on MM cell survival. Quantification of apoptosis through Annexin V/PI staining and FACS analysis (upper panel) and determination of PARP cleavage and Mcl1 protein expression (lower panel) in INA-6 (A-C) or H929 (D, E) silenced for CK1 $\alpha$. CK1 $\alpha$ silencing was obtained with electroporation of ds oligonucleotides directed against CK1 $\alpha$ (A, D) or using IPTG inducible CK1 $\alpha$ shRNA cellular clones (shRNA\#1, shRNA\#2, shRNA\#3, B,C,E). Cells were treated with IPTG $500 \mu$ M (INA-6, and H929 shRNA\#1) or $1000 \mu \mathrm{M}$ (H929 shRNA\#3) for 7 days (INA-6 shRNA\#1, and H929 shRNA\#1 and 2) or 12 days (INA-6 shRNA\#2). For the BM microenvironment model (C) INA-6 wt and shRNA\#1 cells were treated with IPTG $500 \mu \mathrm{M}$ for 6 days and subsequently plated on HS-5 stromal cells for an additional 4 days in the continuous presence of IPTG. In all experiments, IPTG was added also to wt INA-6 cells and H929 cells as control. GAPDH or $\alpha$-tubulin was used as loading control. * indicates $p<0.05$. Data represent the mean \pm SEM of three independent experiments and are presented as arbitrary values over untreated cells. 
degradation cascade. We confirmed that $\mathrm{CK} 1 \alpha$ is a target of Lena in MM cells and showed that its inactivation cooperates with BZ and Lena in inducing MM cell death, even in the protective niche of the BM microenvironment.

In a recent work, Hu et al. demonstrated that CK $1 \alpha$ sustains MM cell survival [24]. However, no studies have investigated whether $\mathrm{CK} 1 \alpha$ inactivation, especially in the MM BM microenvironment, could affect the cytotoxic effects of novel drugs, such as Lena, in the therapy of this hematological malignancy.

According to previous studies [24], we confirmed, in a larger and representative panel, that CSNK1A1 mRNA is overexpressed in MM patients. Interestingly, we demonstrated for the first time a differential CSNK1A1 mRNA expression between the TC groups. In particular, higher levels of CSNK1A1 were associated with TC2 patients, who are characterized by the hyperdiploid status that involves several odd chromosomes including chromosome 5 where CSNK1A1 is located. Among the 30 TC2 cases investigated, 26 (87\%) showed extra copies of chromosome 5 (data not shown), thus suggesting that a gene dosage effect could be partially responsible of the high expression of the CSNK1A1 gene (Figure 1B).

To the best of our knowledge, this is the first report analyzing CK $1 \alpha$ mRNA and protein expression in a large cohort of MM patients both at diagnosis and relapse. To note, we did not observe substantial differences between these two patient groups, suggesting that $\mathrm{CK} 1 \alpha$ levels could not correlate with the clonal evolution of MM plasma cells. We also demonstrated an atypical nuclear diffuse/microspeckled pattern localization in $\mathrm{MM}$ cells, pointing to a myeloma-specific function likely in

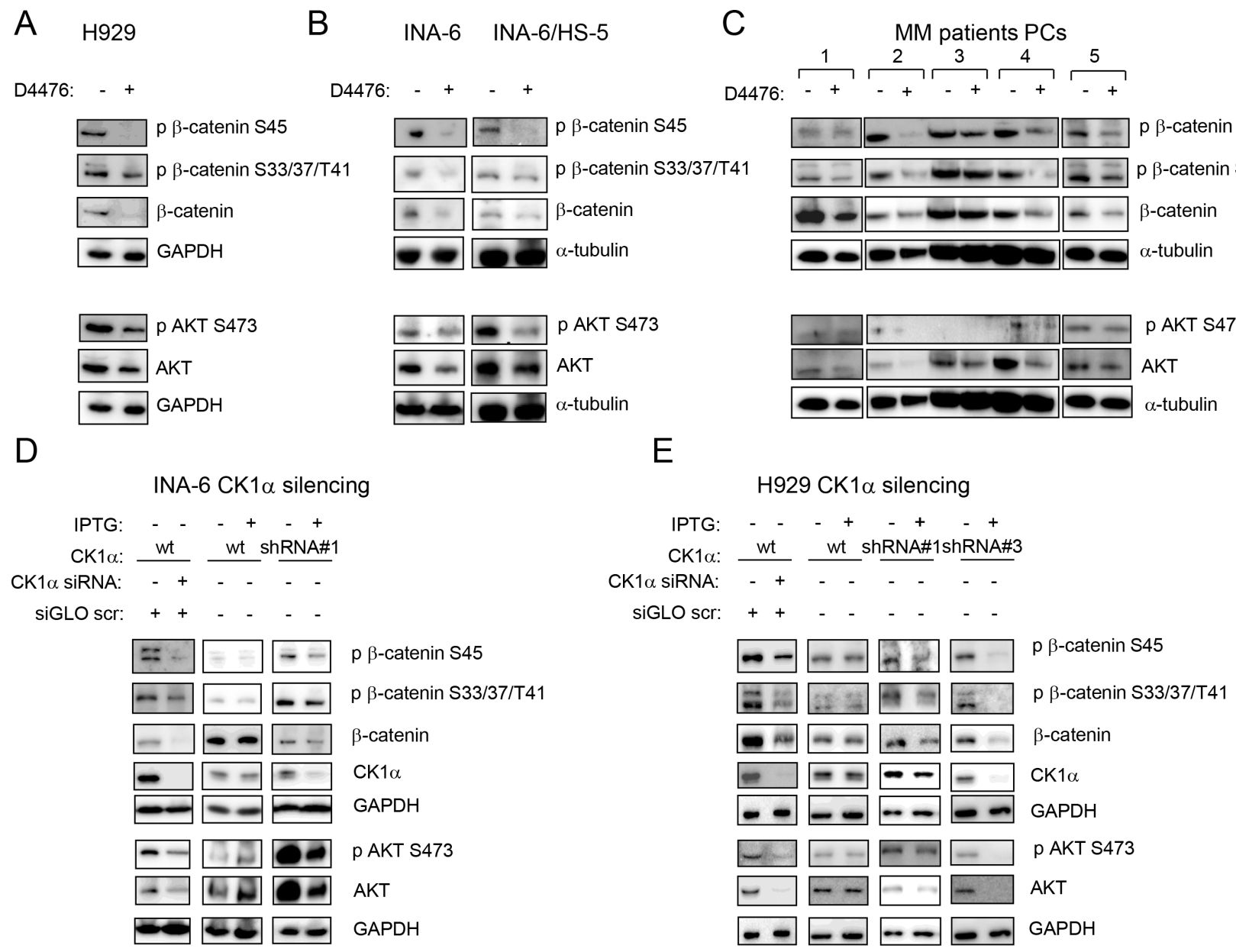

Figure 4: Effects of CK1 inactivation on $\boldsymbol{\beta}$-catenin and AKT signalling pathways. H929 (A), INA-6 grown alone or in coculture with HS-5 (INA-6/HS-5) (B), CD138+ patient derived PCs grown alone or on patient-derived BMSCs or HS-5 (C) were treated with D4476 $40 \mu \mathrm{M}$ (H929 and patient PCs) or $20 \mu \mathrm{M}$ (INA-6) for $48 \mathrm{~h}$ and the expression of phosphorylated $\beta$-catenin on Ser45 (p $\beta$-catenin S45), phospho $\beta$-catenin on Ser33/37/Thr41 (p $\beta$-catenin S33/37/T41), phospho AKT on Ser473 (p AKT S473), total $\beta$-catenin and AKT was evaluated by WB. GAPDH or $\alpha$-tubulin was used as loading control. In C: 1 = MM\#11, 2=co-culture of MM\#12 on BMSC obtained from MM\#28; 3 = co-culture of MM\#12 on BMSC obtained from MM\#8; 4 = co-culture of MM\#12 on HS-5; $5=$ co-culture of MM\#20 on BMSC obtained from MM\#28. The same analysis was performed in INA-6 (D, left panel) or H929 (E, left panel) cells electroporated with ds oligonucleotides against CK1 $\alpha$, in INA-6 wt or INA-6 CK1 $\alpha$ shRNA\#1 cellular clone treated with IPTG $500 \mu$ M for 1 week (D, middle and right panels) or in H929 wt, H929 CK1 $\alpha$ shRNA\#1 and shRNA\#3 clones, treated with IPTG $500 \mu \mathrm{M}$ (H929 wt and shRNA\#1) or $1000 \mu \mathrm{M}$ (shRNA\#3) for 1 week (E, right panel). 
regulating gene transcription and/or chromatin DNA methabolism [13, 32].

The pro-apoptotic effects and alteration of cell cycle related to CK1 $\alpha$ inactivation in MM cells support its pro-survival function in this malignancy. Both CK $1 \alpha$ inhibition and silencing were able to overcome the BM microenvironment-dependent protection (Figures 2 and 3 ). By contrast, CK $1 \alpha$ inhibition did not influence HS-5

A H929 INA-6

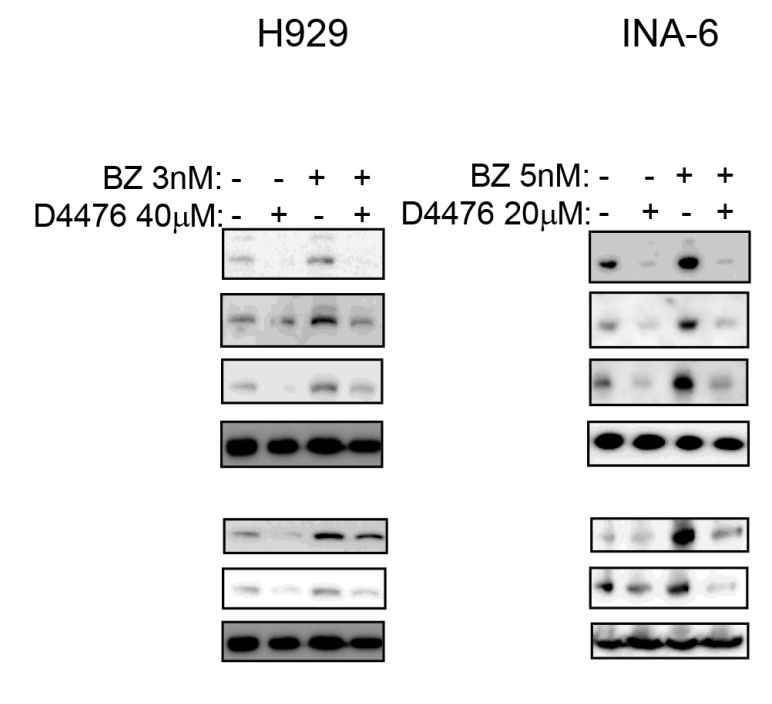

B

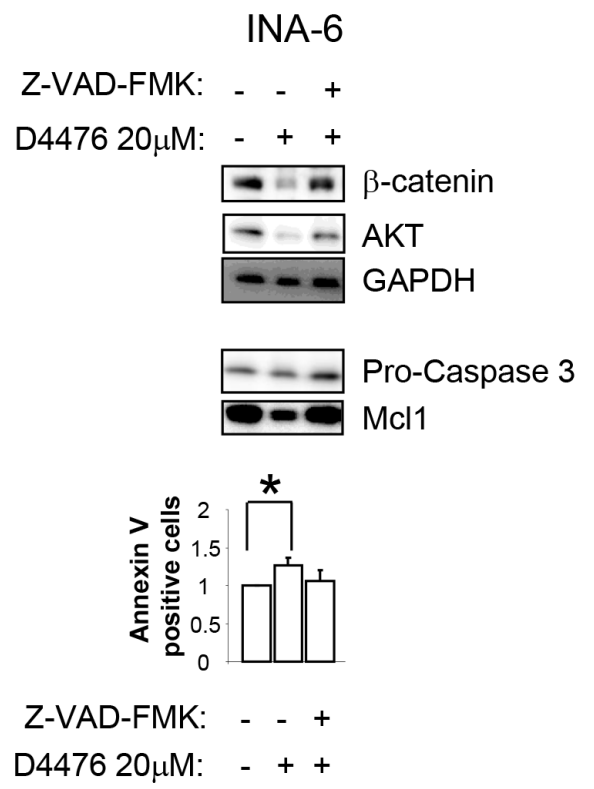

stromal cell or healthy B lymphocytes mortality, suggesting that this effect could be restricted to malignant MM cells.

Unexpectedly, we found that $\beta$-catenin levels decreased upon CK $1 \alpha$ blockade. This was not prevented by proteasome inhibition, but it was rescued by caspase blockade. Similarly, CK1 $\alpha$ inhibition or silencing was accompanied by AKT kinase decrease, in line with what expected according to the

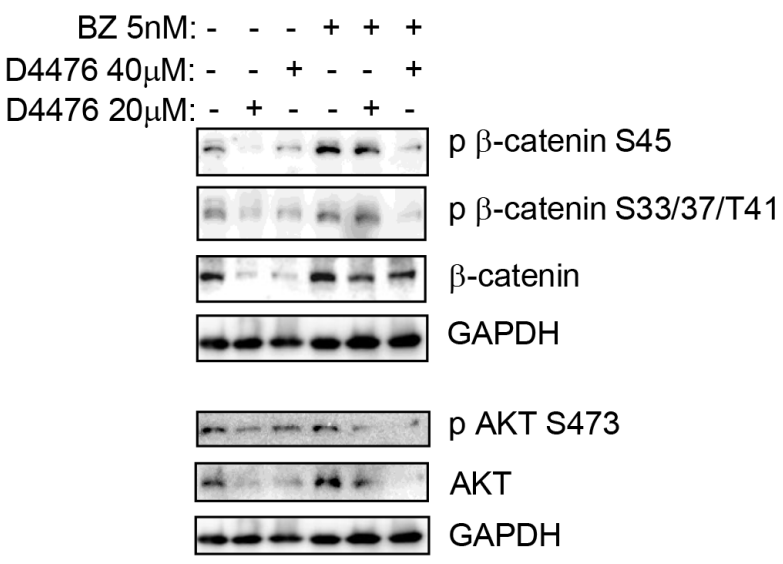

C

INA-6 H929

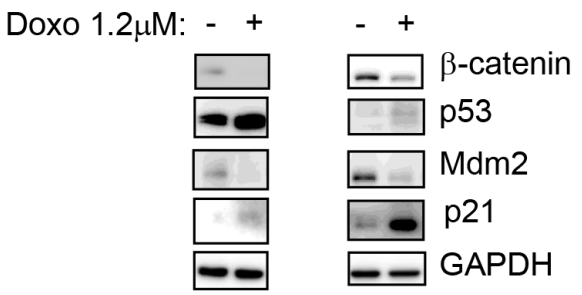

Figure 5: The D4476-dependent reduction of $\beta$-catenin and AKT is independent from the proteasome and is mediated by caspase and p53. (A) Expression of phospho $\beta$-catenin on Ser45 (p $\beta$-catenin S45), phospho $\beta$-catenin on Ser33/37/Thr41 (p $\beta$-catenin S33/37/T41), phosphorylated AKT on Ser473 (p AKT S473) and total $\beta$-catenin and AKT in H929 (left panel) and INA-6 cells, grown alone (middle panel) or in co-culture with HS-5 (INA-6/HS-5, right panel), treated with D4476 for $48 \mathrm{~h}$ and BZ for $18 \mathrm{~h}$ or the combination of the two compounds at the concentrations indicated in the Figure. (B) Expression of total $\beta$-catenin, AKT, Pro-caspase 3 and Mcl1 proteins in INA-6 cells treated with D4476 $20 \mu \mathrm{M}$ in association with Z-VAD-FMK for $48 \mathrm{~h}$. In the combination treatment, cells were pretreated with Z-VAD-FMK $2 \mu \mathrm{M}$ for $1 \mathrm{~h}$ before the addition of D4476. (C) INA-6 and H929 cells were treated with doxorubicin (Doxo) $1.2 \mu \mathrm{M}$ for $18 \mathrm{~h}$. $\beta$-catenin, p53, Mdm2, and p21 were evaluated by WB. In all experiments GAPDH was used as loading control. 
CK1 $\alpha$-mediated inhibition of the AKT inhibitor DEPTOR [14]. Similarly to what demonstrated in lymphoma cells [34], we provided evidence that, also in myeloma cells undergoing p53-dependent apoptosis, AKT is downregulated by a caspase-dependent mechanism.

Moreover, it is known that both AKT $[40,41]$ and CK1 $\alpha$ [18] can phosphorylate and activate Mdm2 with the consequent degradation of p53. In addition, AKT decreases caspase 9 activity by phosphorylation on Ser196 [42], thus promoting cell survival. A reduction in AKT protein level could therefore downmodulate Mdm2 phosphorylation with the subsequent p53 and caspase activation, in a positive feedback loop. The final effect would be the arrest of cell cycle and activation of apoptosis. Since MM cells rely on both $\beta$-catenin and AKT, their downregulation achieved with CK $1 \alpha$ inactivation could be therapeutically relevant. To this regard, the reduction of BZ-induced AKT and $\beta$-catenin accumulation (a possible drawback of BZ) achieved upon CK $1 \alpha$ inhibition may potentially overcome BZ resistance (Figure 5). Indeed, CK1 $\alpha$ inhibition synergically potentiated BZ toxicity in MM (Supplementary Figure 5). To note CSNK1A1 mRNA expression is higher in BZ resistant patients, suggesting the possibility that this kinase might influence the sensitivity to BZ. Importantly, CK $1 \alpha$ inactivation reduced $\beta$-catenin and AKT proteins also in the presence of Lena, and effectively cooperates with this drug in inducing apoptosis and growth arrest, also in the BM microenvironment.

Taken together, our data support an oncogenic role of $\mathrm{CK} 1 \alpha$ in $\mathrm{MM}$, likely by impinging on critical microenvironment dependent survival pathways (Wnt/ $\beta$-catenin and PI3K/AKT). Therefore, it would be worth pursuing to consider the design of novel selective CK1 $\alpha$ inhibitors to be used in the clinical setting in association with conventional or novel antimyeloma agents.

\section{MATERIALS AND METHODS}

\section{Patients and cell cultures}

PBMC, MM and HS-5 cell lines, primary BMSCs from patients were isolated and cultured as previously described $[31,33,43]$. Malignant CD138 ${ }^{+}$PCs and healthy B cells were isolated with EasySep ${ }^{\mathrm{TM}}$ kits (STEMCELL Technologies, USA), after achieving informed consent according to the declaration of Helsinki. The internal Institutional Board approved the use of human material. SaMMi cell line was obtained from a 81 year old woman with a $20 \%$ PCs in the bone marrow. CD138 ${ }^{+}$SaMMi PCs were cultured in DMEM $20 \% \mathrm{FBS}$ with the addition of IL- $62.5 \mathrm{ng} / \mathrm{ml}$. Co-cultures of HS- 5 or BMSCs with INA- 6 or patient derived CD $138^{+}$PCs were stabilized as described in [33]. The clinical features of the patients analyzed and the immunophenotype/karyotype of SaMMi are detailed in Tables 1 and 2.

\section{GEP and data analysis}

The study was performed in a cohort of 165 patients, representative of all the major forms of plasma cell dyscrasia. This dataset, publicly available at the NCBI Gene Expression


Figure 6: Lenalidomide determines CK1 $\alpha$ protein reduction in a dose and time dependent manner. (A) H929 cells were treated with Lena at different concentrations $(1,5,10 \mu \mathrm{M})$ for 7 days (left panel) or with Lena $10 \mu \mathrm{M}$ for 4 (4d) and 7 days (7d). U-266 (B) and INA-6 (C) were treated with Lena $10 \mu \mathrm{M}$ for $4 \mathrm{~h}, 24 \mathrm{~h}$ and $72 \mathrm{~h}$. CK1 $\alpha$, phosphorylated $\beta$-catenin on Ser45 (p $\beta$-catenin S45) and total $\beta$-catenin were evaluated by WB. GAPDH was used as loading control. 
Omnibus repository (accession \#GSE66293), includes 4 normal controls (Voden, Medical Instruments, Italy), 129 MM, 24 primary PCL (pPCL), 12 secondary PCL (sPCL) patients and 18 HMCLs [31]. With the exception of sPCL, the cohort consists of newly diagnosed patients. PCs were purified from BM samples using CD138 immunomagnetic microbeads (MidiMACS system, Miltenyi Biotec, CA, USA). Samples were characterized for the presence of the most frequent chromosomal translocations and the ploidy status based on fluorescence in situ hybridization (FISH) evaluation criteria [44]: 48 showed an HD status; 34 were characterized by the $\mathrm{t}(11 ; 14)$ or $\mathrm{t}(6 ; 14)$ translocations; 19 had the $t(4 ; 14)$ translocation; 6 had either the $t(14 ; 16)$ or $t(14 ; 20)$ translocations; and 22 did not fall into any of the other groups. Details regarding the source of all HMCLs have been previously reported $[31,45,46]$ and recently authenticated by STR profiling and/or gene mutational analyses. For gene expression analysis, samples were profiled on the GeneChip Human Gene 1.0 ST array (Affymetrix, CA, USA) as described [47]. The raw intensity expression values were processed by
Robust Multi-array Average procedure (RMA) [48] with the reannotated Chip Definition Files from BrainArray libraries version 19.0.0, available at http://brainarray.mbni.med.umich.edu.

\section{Cytokines and chemicals}

IL-6 and IPTG were from Sigma-Aldrich (Italy); BZ and Lena from Selleck chemicals (USA); D4476 (4-[4-(2,3-Dihydro-1,4-benzodioxin-6-yl)-5-(2-pyridinyl)$1 \mathrm{H}$-imidazol-2-yl]benzamide) from abcam (UK); Z-VADFMK from Enzo Life Science (UK).

\section{Evaluation of growth and apoptosis}

Apoptosis was assessed by Annexin V/Propidium Iodide (PI) staining (IMMUNOSTEP, Spain) [43]. FACS analysis was performed using a FACSCanto ${ }^{\text {TMCell }}$ Cytometer and the FACSDiva ${ }^{\mathrm{TM}}$ software (BectonDickinson, Italy).
A H929

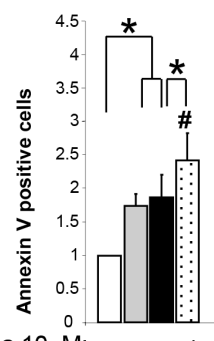

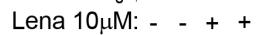

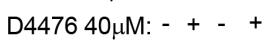

SaMMi

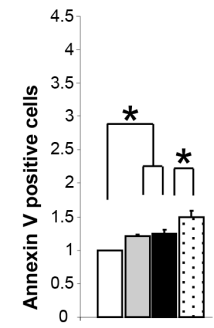

Lena $5 \mu \mathrm{M}:-\cdots+$

D4476 $5 \mu \mathrm{M}:-++$

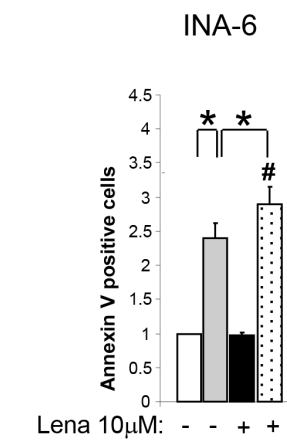

D4476 40uM: - + - +

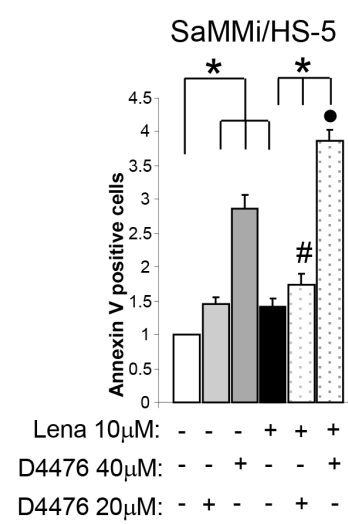

$\mathrm{D}$


H929
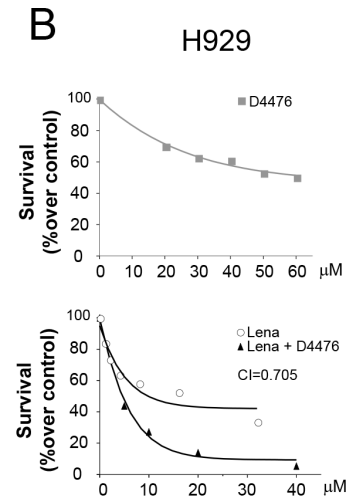

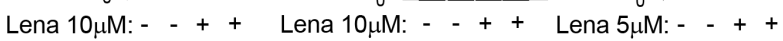

Lena $5 \mu \mathrm{M}:-++$

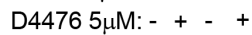

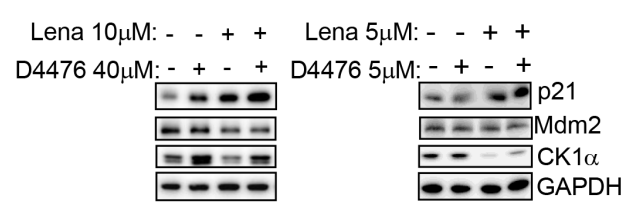

Figure 7: Lenalidomide empowers D4476-induced apoptosis and cell cycle arrest. MM cells were treated with Lena for 3 days (SaMMi, INA-6) or 7 days (H929), with D4476 for the last $48 \mathrm{~h}$ and with the combination of the two compounds at the doses indicated in the Figure. (A) Annexin V/PI staining and FACS analysis of the Lena sensitive cell lines, H929, SaMMi grown alone, or in co-culture with HS-5 (SaMMi/HS-5) and of the Lena resistant INA-6. (B) Synergistic effect of D4476 and Lena in reducing cell viability. Upper graph: dose response curve of $\mathrm{H} 929$ incubated for 72 hours with increasing concentrations of D4476 (grey squared curve). Lower graph: dose-response curve of cells incubated for 1 week with increasing concentrations of Lena alone (white round curve) or Lena plus D4476 (black triangle curve). In the combination treatment, D4476 was added for the last $72 \mathrm{~h}$. Cell viability was assessed with MTT test and reported as percentage over DMSO treated cells. IC50 for D4476 was $60 \mu \mathrm{M}$ and for Lena $10 \mu \mathrm{M}$. The CI between D4476 and Lena was calculated as to be 0.705. (C) Cell cycle analysis with Ki-67/PI staining (left panel) and total Ki-67 (right panel) in H929 and SaMMi cells. * indicates $p<0.05$; \# indicates $p<0.05$ between samples treated with D4476 together with Lena and cells treated only with D4476. Data represent the mean \pm SEM of three independent experiments. (D) Expression analysis of p21, Mdm2 and CK1 $\alpha$ in H929 and SaMMi. GAPDH was used as loading control. 


\section{Assessment of drug concentration-effect and calculation of the combination index (CI)}

H929 cells were plated in triplicate into 96 well plates in $100 \mu \mathrm{l}$ media. D4476, BZ and lenalidomide was added for 72 $\mathrm{h}$ (D4476 and BZ) or 1 week (Lena) alone or in combination. Cell viability was analyzed with 3-(4,5-dimethylthiazol-2-yl)2,5-diphenyltetrazolium bromide (MTT). Cells were washed by centrifugation, resuspended in $100 \mu \mathrm{l}$ of growing media containing $0.25 \mathrm{mg} / \mathrm{ml} \mathrm{MTT}$ and left in the incubator for 2-3 h. Formazan blue precipitates were dissolved in DMSO and absorbance was read at $560 \mathrm{~nm}$. CI was calculated as described in [43].

\section{Cell cycle analysis}

$5 \times 10^{5}$ cells were fixed in ice cold ethanol $70 \% \mathrm{v} / \mathrm{v}$ in PBS for $1 \mathrm{~h}$. After washing in PBS (2 times), samples were stained with PI $(50 \mu \mathrm{g} / \mathrm{ml})$ and RNaseA $0.2 \mathrm{mg} / \mathrm{ml}$ (Sigma-Aldrich, Italy) for $30 \mathrm{~min}$. Ki-67/PI staining was performed using FITC- or PE-conjugated Ki-67 (BD
Pharmingen, Italy). FACS analysis was performed as above.

\section{Immunofluorescence}

It was performed as in [43] with the following antibodies: anti-CK1 $\alpha$ (abcam, UK), secondary AlexaFluor 594-conjugated goat anti-rabbit (Life technologies, Italy). Specimens were mounted in Vectashield medium with DAPI (Vector Laboratories, USA) and analyzed using Leica TCS SP5 confocal microscope, oil objective $63 \mathrm{x}$ with the LAS Advances Fluorescence Leica Application Suite software (Italy).

\section{Western blot (WB)}

WB was performed as described [49]. Antibodies used were the following: CK1 $\alpha$, PARP, Mcl1, Ser45 $\beta$-catenin, Ser33/37/Thr41 $\beta$-catenin, total $\beta$-catenin, Ser473 AKT, total AKT (Cell signaling Technology, MA, USA); Mdm2 (Millipore, Italy), GAPDH (Ambion, USA);



Figure 8: Lenalidomide cooperates with CK1 $\alpha$ silencing in inducing apoptosis and cell cycle arrest, modulating $\boldsymbol{\beta}$-catenin and AKT survival signalling. Ki-67 positive H929 cells after transfection with CK1 $\alpha$ siRNAs and siGLO green indicator and treated for 3 days with Lena (average of five independent experiments). * indicates $p<0.05$. \# indicates $p<0.05$ between samples treated with Lena alone or in combination of CK1 $\alpha$ silencing. Data represent the mean \pm SEM of five independent experiments. The right panel shows a representative Contour Plot. Bottom panel: expression of phosphorylated $\beta$-catenin on Ser45 (p $\beta$-catenin S45), phosphorylated AKT on Ser473 (p AKT S473), total $\beta$-catenin and AKT. GAPDH was used as loading control. 
$\alpha$-tubulin (Sigma-Aldrich, Italy); Bak (Merck, MA, USA); Bax, p21, p53 (Becton Dickinson, Italy); Caspase 3 (Enzo Life Science, UK). Images were acquired using the Image Quant LAS 500 chemiluminescence detection system (GE Healthcare, USA). Densitometric analysis was performed with Quantity One software (Bio-Rad, Italy).

\section{mRNA silencing}

RNAi was performed with nucleofection of ds siRNA and by the generation of inducible shRNA cell lines.

\section{Nucleofection}

Electroporation of INA-6 and H929 was performed as described in [50] with siGLO Green scrambled siRNAs and CK1 $\alpha$ targeting siRNAs ON-TARGETplus SMARTpool siRNA (Thermo Scientific, USA). CK1 $\alpha$ target sequences were: GCGAUGUACUUAAACUAUU; GGAAUCAUUAGGAUAUGUU; AGAGUAACAUGA AAGGUUU; GGCUAAAGgCUGCAACAAA. Cells were harvested at $72 \mathrm{~h}$ after nucleofection.

\section{shRNA lentiviral transduction}

INA-6 and H929 were transduced with the IPTG inducible lentiviral particles carrying CSNK1A1specific shRNA (pLKO_IPTG_3XLacO, SigmaAldrich, Italy). Three independent shRNAs sequences were chosen (TRCN0000006044, named shRNA\#1, TRCN0000006287, named shRNA\#2, TRCN0000006042, named shRNA\#3). $2 \times 10^{4}$ cells were infected with a multiplicity of infection of 5 , using the spinfection method (centrifuged at $1000 \mathrm{~g}$ for $45 \mathrm{~min}$ at $32^{\circ} \mathrm{C}$ ) in the presence of $8 \mu \mathrm{g} / \mathrm{ml}$ polybrene (Sigma-Aldrich, Italy). Puromycin selection $(0.5 \mu \mathrm{g} / \mathrm{ml})$ was initiated two days after transduction. Once a cellular clone was established, to induce $\mathrm{CK} 1 \alpha$ silencing, cells were incubated with $500 / 1000 \mu \mathrm{M}$ IPTG every two/three days for a total of one (in the case of shRNA\#1 and shRNA\#3) or two (in the case of shRNA\#2) weeks, time lapse in which we obtained the best results in terms of CK $1 \alpha$ knockdown efficacy.

\section{Statistical analysis}

Data obtained were evaluated for their statistical significance with the two-tail paired Student's $t$ test or ANOVA analysis of variance with post-hoc corrections, with the Chi square test for trend. Conventional statistical procedures were applied using standard packages of the $\mathrm{R}$ software. Values were considered statistically significant at $p$ values below 0.05 .

\section{ACKNOWLEDGMENTS}

The authors thank AIRC, Italian Ministry of Education and Fondazione Umberto Veronesi for grant support. The authors are grateful to patients for donating samples and to past and present members of the Hematology Unit.

\section{CONFLICTS OF INTEREST}

The authors declare no conflicts of interest

\section{GRANT SUPPORT}

This work was supported by grants from the Associazione Italiana per la Ricerca sul Cancro (AIRC) to FP, GS and AN, from the Italian Ministry of Education, University and Research (FIRB-Futuro in Ricerca 2008 to FP and from the University of Padova (Progetti di ricerca di Ateneo to FP). SM was supported by a Fondazione Umberto Veronesi Fellowship.

\section{Authors' contributions}

Conceived and designed the experiments: SM, FP. Performed the experiments: SM, MC, MM, KG, MC, SCN, LQT, PM, ET, AM. Analyzed the data: SM, MC, MM, AC. Contributed reagents/materials/analysis tools: SM, GB, AN, FP, RZ, LB, LT, GS. Wrote the paper: SM, FP.

\section{REFERENCES}

1. Palumbo A, Anderson K. Multiple myeloma. N Engl J Med. 2011; 364:1046-1060.

2. Morgan GJ, Walker BA, Davies FE. The genetic architecture of multiple myeloma. Nat Rev Cancer. 2012; 12:335-348.

3. Hsu J, Shi Y, Krajewski S, Renner S, Fisher M, Reed JC, Franke TF, Lichtenstein A. The AKT kinase is activated in multiple myeloma tumor cells. Blood. 2001; 98:2853-2855.

4. Derksen PW, Tjin E, Meijer HP, Klok MD, MacGillavry HD, van Oers MH, Lokhorst HM, Bloem AC, Clevers H, Nusse R, van der Neut R, Spaargaren M, Pals ST. Illegitimate WNT signaling promotes proliferation of multiple myeloma cells. Proc Natl Acad Sci USA. 2004; 101:6122-6127.

5. Keane NA, Glavey SV, Krawczyk J, O'Dwyer M. AKT as a therapeutic target in multiple myeloma. Expert Opin Ther Targets. 2014; 18:897-915.

6. Hideshima T, Mitsiades C, Tonon G, Richardson PG, Anderson KC. Understanding multiple myeloma pathogenesis in the bone marrow to identify new therapeutic targets. Nat Rev Cancer. 2007; 7:585-598.

7. Mimura N, Hideshima T, Shimomura T, Suzuki R, Ohguchi H, Rizq O, Kikuchi S, Yoshida Y, Cottini F, Jakubikova J, Cirstea D, Gorgun G, Minami J, et al. Selective and potent Akt inhibition triggers anti-myeloma activities and enhances fatal endoplasmic reticulum stress induced by proteasome inhibition. Cancer Res. 2014; 74:4458-4469.

8. Cheong JK, Virshup DM. Casein kinase 1: Complexity in the family. Int J Biochem Cell Biol. 2011; 43:465-469.

9. Knippschild U, Wolff S, Giamas G, Brockschmidt C, Wittau M, Wurl PU, Eismann T, Stoter M. The role of 
the casein kinase 1 (CK1) family in different signaling pathways linked to cancer development. Onkologie. 2005; 28:508-514.

10. Knippschild U, Gocht A, Wolff S, Huber N, Lohler J, Stoter M. The casein kinase 1 family: participation in multiple cellular processes in eukaryotes. Cell Signal. 2005; 17:675-689.

11. Stamos JL, Weis WI. The beta-catenin destruction complex. Cold Spring Harb Perspect Biol. 2013; 5:a007898.

12. Niehrs C, Shen J. Regulation of Lrp6 phosphorylation. Cell Mol Life Sci. 2010; 67:2551-2562.

13. Knippschild U, Kruger M, Richter J, Xu P, Garcia-Reyes B, Peifer C, Halekotte J, Bakulev V, Bischof J. The CK1 Family: Contribution to Cellular Stress Response and Its Role in Carcinogenesis. Front Oncol. 2014; 4:96.

14. Duan S, Skaar JR, Kuchay S, Toschi A, Kanarek N, BenNeriah Y, Pagano M. mTOR generates an auto-amplification loop by triggering the betaTrCP- and CK1alpha-dependent degradation of DEPTOR. Mol Cell. 2011; 44:317-324.

15. Sarbassov DD, Guertin DA, Ali SM, Sabatini DM. Phosphorylation and regulation of Akt/PKB by the rictormTOR complex. Science. 2005; 307:1098-1101.

16. Venerando A, Marin O, Cozza G, Bustos VH, Sarno S, Pinna LA. Isoform specific phosphorylation of p53 by protein kinase CK1. Cell Mol Life Sci. 2010; 67:1105-1118.

17. Huart AS, MacLaine NJ, Narayan V, Hupp TR. Exploiting the MDM2-CK1alpha protein-protein interface to develop novel biologics that induce UBL-kinase-modification and inhibit cell growth. PloS one. 2012; 7:e43391.

18. Huart AS, MacLaine NJ, Meek DW, Hupp TR. CK1alpha plays a central role in mediating MDM2 control of p53 and E2F-1 protein stability. J Biol Chem. 2009; 284:32384-32394.

19. Elyada E, Pribluda A, Goldstein RE, Morgenstern Y, Brachya G, Cojocaru G, Snir-Alkalay I, Burstain I, Haffner-Krausz R, Jung S, Wiener Z, Alitalo K, Oren M, et al. CKIalpha ablation highlights a critical role for p53 in invasiveness control. Nature. 2011; 470:409-413.

20. Pribluda A, Elyada E, Wiener Z, Hamza H, Goldstein RE, Biton M, Burstain I, Morgenstern Y, Brachya G, Billauer H, Biton S, Snir-Alkalay I, Vucic D, et al. A senescenceinflammatory switch from cancer-inhibitory to cancerpromoting mechanism. Cancer cell. 2013; 24:242-256.

21. Jaras M, Miller PG, Chu LP, Puram RV, Fink EC, Schneider RK, Al-Shahrour F, Pena P, Breyfogle LJ, Hartwell KA, McConkey ME, Cowley GS, Root DE, et al. Csnk1a1 inhibition has p53-dependent therapeutic efficacy in acute myeloid leukemia. J Exp Med. 2014; 211:605-612.

22. Kronke J, Fink EC, Hollenbach PW, MacBeth KJ, Hurst SN, Udeshi ND, Chamberlain PP, Mani DR, Man HW, Gandhi AK, Svinkina T, Schneider RK, McConkey M, et al. Lenalidomide induces ubiquitination and degradation of CK1 alpha in del(5q) MDS. Nature. 2015; 523:183-188.

23. Rena G, Bain J, Elliott M, Cohen P. D4476, a cellpermeant inhibitor of CK1, suppresses the site-specific phosphorylation and nuclear exclusion of FOXO1a. EMBO Rep. 2004; 5:60-65.

24. Hu Y, Song W, Cirstea D, Lu D, Munshi NC, Anderson KC. CSNK1alpha1 mediates malignant plasma cell survival. Leukemia. 2015; 29:474-482.

25. Dickens NJ, Walker BA, Leone PE, Johnson DC, Brito JL, Zeisig A, Jenner MW, Boyd KD, Gonzalez D, Gregory WM, Ross FM, Davies FE, Morgan GJ. Homozygous deletion mapping in myeloma samples identifies genes and an expression signature relevant to pathogenesis and outcome. Clin Cancer Res. 2010; 16:1856-1864.

26. Zhan F, Barlogie B, Arzoumanian V, Huang Y, Williams DR, Hollmig K, Pineda-Roman M, Tricot G, van Rhee F, Zangari M, Dhodapkar M, Shaughnessy JD, Jr. Geneexpression signature of benign monoclonal gammopathy evident in multiple myeloma is linked to good prognosis. Blood. 2007; 109:1692-1700.

27. Agnelli L, Mosca L, Fabris S, Lionetti M, Andronache A, Kwee I, Todoerti K, Verdelli D, Battaglia C, Bertoni F, Deliliers GL, Neri A. A SNP microarray and FISH-based procedure to detect allelic imbalances in multiple myeloma: an integrated genomics approach reveals a wide gene dosage effect. Genes Chromosomes Cancer. 2009; 48:603-614.

28. Carrasco DR, Tonon G, Huang Y, Zhang Y, Sinha R, Feng B, Stewart JP, Zhan F, Khatry D, Protopopova M, Protopopov A, Sukhdeo K, Hanamura I, et al. Highresolution genomic profiles define distinct clinicopathogenetic subgroups of multiple myeloma patients. Cancer cell. 2006; 9:313-325.

29. Agnelli L, Bicciato S, Mattioli M, Fabris S, Intini D, Verdelli D, Baldini L, Morabito F, Callea V, Lombardi L, Neri A. Molecular classification of multiple myeloma: a distinct transcriptional profile characterizes patients expressing CCND1 and negative for 14q32 translocations. J Clin Oncol. 2005; 23:7296-7306.

30. Hideshima T, Bergsagel PL, Kuehl WM, Anderson KC. Advances in biology of multiple myeloma: clinical applications. Blood. 2004; 104:607-618.

31. Lionetti M, Barbieri M, Todoerti K, Agnelli L, Marzorati S, Fabris S, Ciceri G, Galletti S, Milesi G, Manzoni M, Mazzoni M, Greco A, Tonon G, et al. Molecular spectrum of BRAF, NRAS, KRAS gene mutations in plasma cell dyscrasias: implication for MEK-ERK pathway activation. Oncotarget. 2015; 6:24205-24217. doi: 10.18632/oncotarget.4434.

32. Gross SD, Anderson RA. Casein kinase I: spatial organization and positioning of a multifunctional protein kinase family. Cell Signal. 1998; 10:699-711.

33. Manni S, Toscani D, Mandato E, Brancalion A, Quotti Tubi L, Macaccaro P, Cabrelle A, Adami F, Zambello R, Gurrieri C, Semenzato G, Giuliani N, Piazza F. Bone marrow stromal cell-fueled multiple myeloma growth and osteoclastogenesis are sustained by protein kinase CK2. Leukemia. 2014; 28:2094-2097.

34. Gottlieb TM, Leal JF, Seger R, Taya Y, Oren M. Cross-talk between Akt, p53 and Mdm2: possible implications for the 
regulation of apoptosis. Oncogene. 2002; 21:1299-1303.

35. Sadot E, Geiger B, Oren M, Ben-Ze'ev A. Down-regulation of beta-catenin by activated p53. Mol Cell Biol. 2001; 21:6768-6781.

36. Brancolini C, Lazarevic D, Rodriguez J, Schneider C. Dismantling cell-cell contacts during apoptosis is coupled to a caspase-dependent proteolytic cleavage of beta-catenin. J Cell Biol. 1997; 139:759-771.

37. Van de Craen M, Berx G, Van den Brande I, Fiers W, Declercq W, Vandenabeele P. Proteolytic cleavage of betacatenin by caspases: an in vitro analysis. FEBS Lett. 1999; 458:167-170.

38. Bisping G, Wenning D, Kropff M, Gustavus D, MullerTidow C, Stelljes M, Munzert G, Hilberg F, Roth GJ, Stefanic M, Volpert S, Mesters RM, Berdel WE, et al. Bortezomib, dexamethasone, and fibroblast growth factor receptor 3-specific tyrosine kinase inhibitor in $\mathrm{t}(4 ; 14)$ myeloma. Clin Cancer Res. 2009; 15:520-531.

39. Mulligan G, Mitsiades C, Bryant B, Zhan F, Chng WJ, Roels S, Koenig E, Fergus A, Huang Y, Richardson P, Trepicchio WL, Broyl A, Sonneveld P, et al. Gene expression profiling and correlation with outcome in clinical trials of the proteasome inhibitor bortezomib. Blood. 2007; 109:3177-3188.

40. Mayo LD, Donner DB. A phosphatidylinositol 3-kinase/ Akt pathway promotes translocation of Mdm2 from the cytoplasm to the nucleus. Proc Natl Acad Sci USA. 2001; 98:11598-11603.

41. Zhou M, Gu L, Findley HW, Jiang R, Woods WG. PTEN reverses MDM2-mediated chemotherapy resistance by interacting with p53 in acute lymphoblastic leukemia cells. Cancer Res. 2003; 63:6357-6362.

42. Carnero A. The PKB/AKT pathway in cancer. Curr Pharm Des. 2010; 16:34-44.

43. Manni S, Brancalion A, Tubi LQ, Colpo A, Pavan L, Cabrelle A, Ave E, Zaffino F, Di Maira G, Ruzzene M, Adami F, Zambello R, Pitari MR, et al. Protein kinase CK2 protects multiple myeloma cells from ER stress-induced apoptosis and from the cytotoxic effect of HSP90 inhibition through regulation of the unfolded protein response. Clin Cancer Res. 2012; 18:1888-1900.
44. Agnelli L, Fabris S, Bicciato S, Basso D, Baldini L, Morabito F, Verdelli D, Todoerti K, LambertenghiDeliliers G, Lombardi L, Neri A. Upregulation of translational machinery and distinct genetic subgroups characterise hyperdiploidy in multiple myeloma. $\mathrm{Br} \mathrm{J}$ Haematol. 2007; 136:565-573.

45. Lombardi L, Poretti G, Mattioli M, Fabris S, Agnelli L, Bicciato S, Kwee I, Rinaldi A, Ronchetti D, Verdelli D, Lambertenghi-Deliliers G, Bertoni F, Neri A. Molecular characterization of human multiple myeloma cell lines by integrative genomics: insights into the biology of the disease. Genes Chromosomes Cancer. 2007; 46:226-238.

46. Verdelli D, Nobili L, Todoerti K, Mosca L, Fabris S, D’Anca M, Pellegrino E, Piva R, Inghirami G, Capelli C, Introna $\mathrm{M}$, Baldini L, Chiaramonte $\mathrm{R}$, et al. Molecular events underlying interleukin-6 independence in a subclone of the CMA-03 multiple myeloma cell line. Genes Chromosomes Cancer. 2014; 53:154-167.

47. Todoerti K, Agnelli L, Fabris S, Lionetti M, Tuana G, Mosca L, Lombardi L, Grieco V, Bianchino G, D’Auria F, Statuto T, Mazzoccoli C, De Luca L, et al. Transcriptional characterization of a prospective series of primary plasma cell leukemia revealed signatures associated with tumor progression and poorer outcome. Clin Cancer Res. 2013; 19:3247-3258.

48. Irizarry RA, Hobbs B, Collin F, Beazer-Barclay YD, Antonellis KJ, Scherf U, Speed TP. Exploration, normalization, and summaries of high density oligonucleotide array probe level data. Biostatistics. 2003; 4:249-264.

49. Piazza F, Manni S, Tubi LQ, Montini B, Pavan L, Colpo A, Gnoato M, Cabrelle A, Adami F, Zambello R, Trentin L, Gurrieri C, Semenzato G. Glycogen Synthase Kinase-3 regulates multiple myeloma cell growth and bortezomibinduced cell death. BMC Cancer. 2010; 10:526.

50. Manni S, Brancalion A, Mandato E, Tubi LQ, Colpo A, Pizzi M, Cappellesso R, Zaffino F, Di Maggio SA, Cabrelle A, Marino F, Zambello R, Trentin L, et al. Protein kinase CK2 inhibition down modulates the NFkappaB, STAT3 survival pathways, enhances the cellular proteotoxic stress and synergistically boosts the cytotoxic effect of bortezomib on multiple myeloma and mantle cell lymphoma cells. PloS one. 2013; 8:e75280. 